This document is the accepted manuscript version of the following article:

Cherunya, P. C., Ahlborg, H., \& Truffer, B. (2020). Anchoring innovations in oscillating domestic spaces: why sanitation service offerings fail in informal settlements. Research Policy, 49(1), 103841 (16 p.).

https://doi.org/10.1016/j.respo1.2019.103841

This manuscript version is made available under the CC-BY-NC-ND 4.0

1icense http://creativecommons.org/1icenses/by-nc-nd/4.0/

\title{
Anchoring innovations in oscillating domestic spaces: Why sanitation service offerings fail in informal settlements
}

Pauline Cherunya ${ }^{1,2, *}$ Helene Ahlborg ${ }^{3,4}$, Bernhard Truffer ${ }^{1,2}$

1: Department of Environmental Social Sciences, Eawag, Switzerland

2: Copernicus Institute of Sustainable Development, Utrecht University, the Netherlands

3: School of Global Studies, Gothenburg University, Sweden

4: Department of Technology Management and Economics, Chalmers University of Technology, Gothenburg, Sweden

* Corresponding Author:

Department of Environmental Social Sciences,

Eawag: Swiss Federal Institute of Aquatic Science and Technology,

Ueberlandstrasse 133, 8600 Duebendorf, Switzerland.

Email address: pauline.cherunya@eawag.ch

\section{Highlights}

- $\quad$ Proposes a context-sensitive and actor-centred approach to analysing the embedding of innovations

- $\quad$ Context for users' daily practices is conceptualized as oscillating domestic spaces

- $\quad$ Reflects the need to develop multiple alternatives and partial solutions when services are fragmented and unreliable

- Extends the conventional practice-theoretical analysis by operationalizing 'time-space'

- $\quad$ Proposed concept may be useful also for global North contexts where service systems are becoming more heterogeneous and user-centred

\section{Abstract}

A persistent conundrum for practitioners and researchers in the development context is that, often, newly provided and improved basic services are not maintained by users despite seemingly superior functionality and user convenience. We argue that one major reason for this is an insufficient understanding of the context in which users have to manage their daily lives. We therefore propose an approach to analysing the embedding of basic services that focuses on the users' daily practices. We do so by borrowing insights from 'socio-technical transitions' and 'practice theory' in developing our concept of oscillating domestic spaces. The concept reflects the need for people to constantly respond to quickly changing and precarious circumstances by rearranging their daily practices in time and space and developing a multiplicity of alternative options and partial solutions. We illustrate the analytical approach in a case study of sanitation access in informal settlements of Nairobi, Kenya. The analysis shows how the introduction of a container-based toilet resulted in partial embedding. The innovation 
anchored to only a part of the oscillating domestic spaces and was in disarray with the needs of users most of the time. The conceptual approach contributes to the understanding about how users take part in sustainability transitions as well as the added value of the time-space dimension in analysing practices in highly complex contexts. We conclude by reflecting on the potential applicability of the analytical approach to transition cases in the global North.

\section{Keywords}

Practice Theory; Socio-technical transitions; Oscillating domestic spaces; Sanitation; Global South

\section{Introduction}

Around the world, actors are engaged in processes of improving basic service access and well-being for the one billion people living in informal settlements (slums ${ }^{1}$ ) (Ezeh et al., 2017; UN Habitat, 2016; Sheuya, 2008). Informal settlements in quickly growing cities provide fertile ground for innovation by presenting numerous challenging problems requiring solutions. However, the high level of complexity and multi-dimensional poverty defeats many hopeful attempts at rolling out novel solutions for hygienic, safe, affordable, and consistent access to water, sanitation, energy, housing or waste management. In this article, the starting point is the question: why do so many innovations introduced to informal settlements fail to embed and replace the existing practices that innovators see as undesirable? Attempting to understand this failure ${ }^{2}$ and what it takes for innovations to embed, we develop a conceptual approach that enables us to understand service provision and use from the perspective of users and their daily realities.

In Sub-Saharan Africa, the persistence of unequally distributed and unsustainable basic service systems result from a combination of historical and current processes, with institutional, economic, political, infrastructural, demographic and social factors creating a complex situation that is difficult to understand and tackle (Beall et al., 2010; Jaglin, 2016). Public utility actors often lack technical, institutional and financial capacities, sometimes also the motivation, to extend services into informal settlements (O'Keefe et al., 2015; van Welie et al., 2019). These areas are often characterised by overcrowding, tenure legality problems, insecurity and high rates of unplanned expansions (Andersson et al., 2016; O’Keefe et al., 2015). Large-scale public service provision, such as utilities delivering electricity, drinking water and sewage systems, often reach only higher-income urban

\footnotetext{
${ }^{1}$ We use the term 'informal settlement' and refer to settlements characterized by at least some of the following features: a lack of formal recognition of the settlement and its residents by local governments; the absence of secure tenure for residents; inadequacies in basic service provision; overcrowded and sub-standard dwellings; and location on land not suitable for occupation. 'Slum' is broadly used in research and practice as an alternative term but usually has derogatory connotations. For more discussion on this see Bartlett, $\mathrm{S}$., Satterthwaite, D., 1989. Introduction: Beyond the Stereotype of Slums. Environment and Urbanization 1, 2-5.

${ }^{2}$ We define 'failure' from the perspective of many innovators as the inability of a new service offering to gain prominence and quickly replace existing less desirable options and practices (i.e. container-based toilets replacing open defecation) which contribute to inability of innovations to quickly scale up.
} 
neighbourhoods, and there exists a patchwork of overlapping but fragmented and poorly aligned service systems that inadequately serve informal settlement dwellers (van Welie et al., 2018)

Sanitation, in particular, faces some of the greatest transformation challenges for global South ${ }^{3}$ cities and, so far, there has been little progress. For example, the Millennium Development Goals for sanitation were not met by great margins (UNSD, 2015). Increasingly, public and private sector actors are engaging in the sanitation sector, attempting to provide alternative service provision models. Compared to large-scale centralized models, decentralized and small-scale sanitation systems are suggested to offer possibilities for rapid installations, cost reductions, local adaptation to available spaces and to preferences, and possibilities for local experimentation and learning (Katukiza et al., 2012; Larsen et al., 2016; O'Keefe et al., 2015). However, while the potential merits of small-scale systems are many, the successes are few, with many not being maintained by users, failing to replace non-desirable artefacts and practices and failing to scale up beyond pilot projects (Bhagwan et al., 2008; Lüthi et al., 2010; Sijbesma, 2006).

We argue that these failures result, to a large degree, from insufficient understanding of the context in which these innovations are introduced and from a lack of adequate engagement with users throughout the innovation process. Whereas conventional approaches to introducing new service options in engineering, economics and psychology are technology and product-oriented (Ockwell et al., 2018; Ramani et al., 2012), it is an established insight in development studies and socio-technical transition studies that innovation aiming at user embedding should be needs-driven and contextsensitive (Hansen and Coenen, 2015; Korten, 1980; Satterthwaite et al., 2015). In development practice, however, users are too often treated as either passive adopters in innovation processes, with their agency and role as co-innovators overlooked, or are perceived as free-floating individuals making rational choices on a market (Dreibelbis et al., 2013; Letema et al., 2014; Ostrom, 1996; Schramm and Wright-Contreras, 2017). Furthermore, Ramani et al. (2012) and Rogers (2010) argue that there continues to be undue focus on the supply-side. The process of how new service offerings become appropriated and reshaped in the contingencies of everyday activities and by users with multiple, sometimes conflicting obligations, needs, and priorities, is overlooked and remains understudied. A combination of the shallow understanding of context and limited engagement with imagined 'beneficiaries' not only prevent well-tailored service offerings, but also lead supply-side actors to entertain somewhat unrealistic assumptions about the successful embedding of their solutions.

\footnotetext{
3 The terms 'global South' and 'global North' in this paper are used to replace the more conventional terms 'developing' and 'developed' countries for the sake of emphasizing the need for a shift from the modernist perspectives on development as a predictable and linear process unaffected by political and economic relations between countries. For more discussion on this see, Edelman, M., Haugerud, A., 2005 Introduction: the anthropolgy of development and globalization. Edelman, Marc; Haugerud, Angelique. The anthropology of development and globalization: from classical political economy to contemporary neoliberalism. Malden, MA: Blackwell.
} 
When Satterthwaite et al. (2015) analysed the progress framework for the Sustainable Development Goals (SDGs), they found that it is still standard development practice to ignore contextual dimensions and basic realities on the ground when setting objectives or undertaking interventions. They found that the entire statistical base for assessing progress within the United Nations' targets on sanitation defines improved provision the same way for all areas, without concern for space and density, occupations, whether rural or urban, housing designs etc. Based on our own review on how the 'sanitation ladder' is specified in the SDGs, we find that it maintains a rather linear and mechanist categorization by specifying the following access levels: open defecation, unimproved, limited, basic and safely managed (WHO/UNICEF, March 2018). Further, these levels are reached without sufficiently accounting for everyday precarities in service provision and access (i.e. if there is consistent provision of and access to sanitation). We therefore suggest that context is overlooked not only in practice but also in policy.

The aim of this paper is to contribute to a context-sensitive and actor-centred perspective on innovation processes by considering conditions for the successful introduction, acceptance, and embedding of new service offerings in informal settlements. We position ourselves in the literature on sustainability transitions. Our specific vantage point is a 'socio-technical system' which refers to a broad, but tightly interrelated, variety of institutional elements (societal and technical norms, regulations, standards of good practice, public opinions, and user practices), material artefacts and infrastructures, as well as agency in networks of actors dependent on each other (Fünfschilling, 2014; Geels, 2011; Markard et al., 2012). Transitions entail processes that lead to a fundamental shift in the basic configuration of a socio-technical system (Markard et al., 2012). In particular, we build on 'sociotechnical transitions' and 'practice theory' to develop a novel conceptual approach to studying transitions in contexts characterized by high complexity, fragmentation and uncertainty as compared to the 'usual focus' in this field-the centralised, stable and relatively homogenous sectors of basic service provision in OECD contexts (van Welie et al., 2018).

The main contribution of this paper is elaborating the concept of the oscillating domestic spaces, which makes visible how people are faced with constant fluctuations-expected and unexpected-in the conditions that enable service access. As people go about their daily tasks, they are forced to respond to precarious situations by adopting a multiplicity of complementary and partial solutions. This manoeuvring manifests itself in ongoing adjustments-i.e. oscillating daily space-time patternsin how, when, and where practices are carried out. This has consequences for the potential acceptance and embedding of new innovations. We illustrate the virtues of this analytical approach in an empirical case study of sanitation in the informal settlements of Nairobi, in Kenya. 
For scholars and practitioners involved in basic service delivery in poor urban communities, the approach helps improve the understanding about the processes of embedding and inspires contextsensitive and needs-driven solutions. The approach suggests that there is a need to align expectations around success with the reality of users in the informal settlements. We argue that a careful consideration of the context in which people go about their daily lives leads to a more modest understanding of what constitutes a 'successful' innovation-reflecting the need for multiple and partial solutions rather than a silver-bullet approach.

Importantly, we think that the approach has significance beyond the empirical field of sanitation in informal settlements in African cities. There are two conceptual contributions to the literature on 'sustainability transitions' emerging from the analysis. First, research on transitions has often focused on purposeful interactions between state and market actors in their attempts to achieve certain goals. Considerably less attention has been directed towards understanding how demand-side actors in their everyday lives and activities are part of transitions to sustainability (Avelino et al., 2016; Fischer and Newig, 2016; Wittmayer et al., 2016). The approach taken here, to place the daily practices of users at the core of the analysis, shows how relevant it is to understand their agency in order to identify the conditions for systemic change. In particular, we follow Ahlborg (2017) and Shove and Walker (2007), who have pointed to the risk that socio-technical system approaches that do not theoretically and methodologically pay attention to demand-side actors' logics, roles, and practices could become overly technocratic and consequently disregarding or downplaying human needs, political struggles, and conflicts of interest inherent in societal transitions. The use of practice theory-which has already been operationalized within socio-technical transitions by several researchers-is helpful for counteracting this shortcoming (Shove and Walker, 2007).

Second, the literature on transitions has been developed based largely on empirical experiences in a few OECD countries and industrial sectors, and only recently have other geographical and sectorial contexts been explored (van Welie et al., 2018; Wieczorek, 2017; Yap and Truffer, 2019). Our second contribution is thus to operationalize a practice-oriented approach to studying transitions in contexts riddled with uncertainty, heterogeneity, and fragmentation with regard to service provision arrangements. Our conceptual framework builds on the 'time-space' dimension of practices, which becomes more critical analytically in highly complex contexts. This is typical for informal settlements in global South cities but may also be relevant for other contexts with similar characteristics.

The paper is structured as follows: The next section reviews literature on practice theory and its integration with socio-technical transitions literature, and also elaborates on the analytical approach we propose. Section three introduces the empirical case study of sanitation in Nairobi's informal settlements and describes the research methodology. The results section summarizes the case 
evidence and illustrates the complexities that informal settlement dwellers are confronted with daily when taking care of their domestic and sanitation needs. We highlight an attempt at introducing a new service offering, a container-based toilet, which had been envisioned by innovators as an in-house family toilet and would also solve the problem of 'open defecation' and 'flying toilets' ${ }^{4}$. Our analysis explains why the innovation became only partially embedded and why it didn't replace these inferior sanitation practices. Section 5 discusses the implication of the findings for research and practice. We conclude by commenting on the usefulness of the analytical approach for socio-technical transitions in other sectors and geographies.

\section{Theory}

\subsection{A practice-theoretical understanding of socio-technical transitions and limitations}

Socio-technical transitions are processes that lead to a fundamental shift in socio-technical systems and involve far-reaching changes along technological, material, organizational, institutional, political, economic and socio-cultural dimensions as well as in terms of everyday user practices (Markard et al., 2012). In analysing the systemic changes that are triggered by innovations, practice theory is increasingly used as an approach that takes practices, rather than structural features or individual rational choices, to be the foundation in understanding the 'social' in socio-technical transitions (Cetina et al., 2005; Shove, 2004). Practices are considered 'sites' of the social that can reveal key insights into the ways and means through which organizations and socio-technical regimes operate and change over time (Schatzki, 2002). Practice theory is strongly associated with, and builds upon, early works of Giddens (1979, 1984), Bourdieu (1980), Wenger (1998), Reckwitz (2002), and Schatzki (2002). For Giddens (1979), practices are understood as foundational building blocks of society that reflect the relationships between actions in everyday life worlds and the long-standing structures that govern and mediate these. In this understanding, a focus on practices can overcome the structureactor dualism, a problem encountered and discussed in many fields, including earlier formulations of transition frameworks (Spaargaren et al., 2013).

A number of more recent studies have involved themselves in bridging practice thinking and transition studies. They include studies on food systems (Cohen and Ilieva, 2015; Hargreaves et al., 2013; Spaargaren et al., 2013), energy (Boamah and Rothfuß, 2018; Gram-Hanssen, 2011; Greene, 2018; Ulsrud et al., 2018), transport and mobility (Shove and Walker, 2010; Watson, 2012), showering (Shove

\footnotetext{
${ }^{4}$ Open defecation is when people defecate in the open environment rather than into a toilet (I.e. in fields, bushes, forests, ditches, canals or other open spaces). Flying toilet is a local term in informal settlements in Kenya and refers to the strategy of defecating into a plastic bag while inside the home and throwing the waste, unnoticed, into the open environment. These strategies are performed because of a lack of toilet access.
} 
and Walker, 2010), sanitation (van Welie et al., 2018), and several conceptual discussions (McMeekin and Southerton, 2012; Shove et al., 2012; Shove and Walker, 2007; Stengers, 2010). For Hargreaves et al. (2013), they understand humans as skilled agents who actively negotiate and perform a wide range of practices in the normal course of everyday life. People perform practices while embedded in webs of relations between human actors and non-human elements (Stengers, 2010), and such practices are shaped by and reshape the context of which they are part.

Shove and Walker (2007) indicate that practice-oriented approaches make studies of systems in transition less retrospective and distanced, and in this way are better able to make propositions about how individuals and organisations can act to steer transitions. The added advantages of a practice theory approach also include giving attention to the agency of the demand-side, that is, to the role of citizens as part of a transition (Shove and Walker, 2007), and, as well, being able to give equal attention between a novel service offering and the other inconspicuous artefacts and activities that the new offering competes with, replaces or becomes an embedded part of (Hargreaves et al., 2013; Shove and Walker, 2007).

Practices are defined as spatially and temporally organised 'ways of doing' certain activities, with a recognizable conjunction of interlinked elements (Schatzki, 2002; Shove et al., 2012). Practice elements are delineated as: materials - the technical infrastructures and artefacts; meanings - the images, symbols, rationales, and perceptions; and competences - the know-how (Hargreaves et al., 2013; Shove et al., 2012).

Figure 1: The interlinked elements that make up a practice

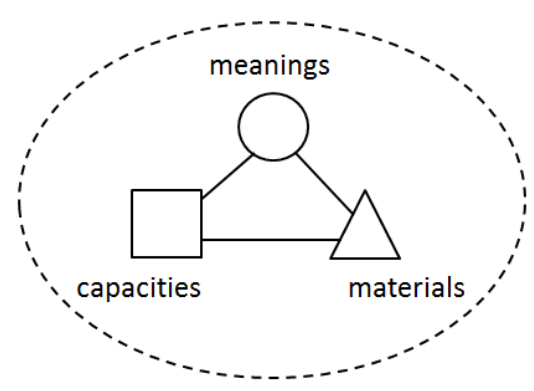

In the domains of everyday life, practices co-exist and elements may overlap across practices. Consider, for example, cooking, which combines materials (ingredients; gas-cooker), meanings (diet choices; assumed responsible; preferred cooking times), and competences (know-how of using the stove; skills of cooking certain dishes). Cooking is also linked to other, analytically distinguishable, practices of acquiring the ingredients, eating and cleaning the kitchen. The co-existence of practices is conceptualized as 'ecologies' and 'bundles' of practices respectively by Stengers (2013) and Shove et al. (2012). The bundling can occur by overlap of elements (Shove et al., 2012), such as when both 
practices of room-heating and cooking require the same material element - energy (Figure 2); or in the form of sequencing of different practices in time and space (Shove et al., 2009), i.e. establishing a daily schedule of cooking-eating-cleaning (Figure 3). Users develop routines across different activitydomains for plural reasons-reflecting meanings, taste, comfort, and resource maximization (Shove et al., 2012), as well as necessity, constraint, or obligation.

Figure 2: Bundling by overlap of elements

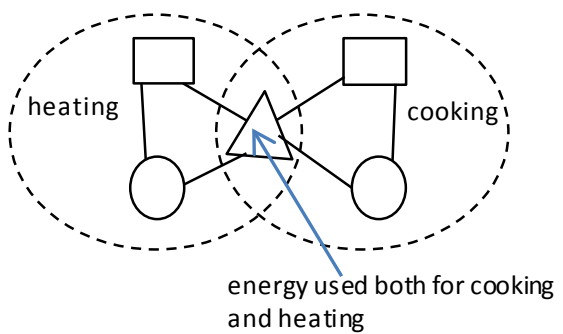

Figure 3: Bundling by sequencing different practices over time

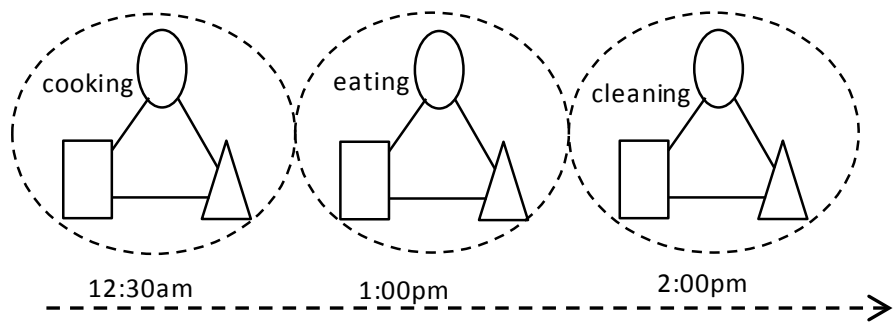

The bundling of practices is significant for the maintenance, stabilization and reproduction of a practice (Watson, 2012). Bundling can become routinized and the consequences of the performance of routinized practices can persist in the temporal-spatial fabric of society (Jones and Murphy, 2011; Watson, 2012). The stabilization of arrangement of practice elements and bundles (socio-technical configurations), which scale up and gain momentum over time and in space, at some point become what we understand as 'structures' or socio-technical 'regimes' (Hargreaves et al., 2013). Hence it is suggested that the disentanglement of the space-time provides a useful analytical approach to understanding the interplay of individual and structural constituents of social phenomena (Jones and Murphy, 2011; Shove et al., 2012; Watson, 2012).

Though acknowledged as an important function, application of the time-space dimension has often been implicit or simplified in the analysis of practices. Operationalization of the time-space has largely focused on optimisation of time-resources as practices become "overall more demanding and hungrier of time" (Shove et al., 2012). What we can see in the literature is that the main focus in analysing the everyday practice dynamics has been on structuring the temporal rhythms of daily life or on rescheduling activities over time, (i.e. studies by Shove et al. (2009) and Watson (2012)). Less attention has been given to the space dimension. We suggest that the time-space, together, becomes a more critical element analytically in situations where practice elements-required to perform a specific practice-are diverse, often spatially dispersed, and their availability is precarious, as is the situation in basic service access in cities in the global South, and more prominently in informal settlements.

How practice theory has been integrated into transition studies has been largely informed by empirical case studies from the global North. Only three studies from the global South are known to the authors, these being: Boamah and Rothfuß (2018) and Ulsrud et al. (2018) on solar PV in Ghana and Kenya and 
van Welie et al. (2018) on sanitation in Nairobi. In our view, the current application of practice theory to study sustainability transitions is not well suited for understanding practices in cities in the global South because the contexts are fundamentally different: Basic service access in informal settlements is characterized by inadequate and inconsistent provision, there is high levels of poverty among users, and varieties of formal and informal service options co-exist. These aspects present a lot of difficulties and uncertainties for users. In contrast, in cities in the global North, there is more certainty about how, where and when to undertake a task because conditions for performance of practices are rather stable. This is by virtue of reliable and adequate infrastructures, efficient monitoring of basic service systems, and much more stable financial conditions of most individuals with regard to accessing basic necessities (such as domestic water supply, solid waste management, and public transport). We could also argue that less socio-cultural diversity is a contributing factor. Contextual differences may require adaptation of analytical concepts. For example, in the analysis of sanitation provision practices in global South cities, van Welie et al. (2018) had to specify five (instead of three) practice dimensions in order to adequately differentiate sanitation service regimes. Boamah and Rothfuß (2018) and Ulsrud et al. (2018), took a rather simplified application of a practice analysis by focusing on the interactions between beneficiaries and the novel solar lighting technologies. They paid less attention to the bundling of practices and everyday contingencies in space and time - aspects this present paper attempts to contribute.

For our empirical context, we find it necessary to bring out more explicitly the time-space aspects of practices in the analysis in order to deal with the uncertainties, fragmentation and the complex bundling of practices. From this perspective, we suggest that the introduction of an innovation leads to an intricate reconfiguration of the other normal inconspicuous activities and practices that the innovation competes with, replaces or becomes an embedded part of. Figure 4 below uses the spacetime path concept (Hägerstrand, 1970) to illustrate the bundling of practices over time and in space, yielding a typical representation of domestic activities in an informal settlement. 


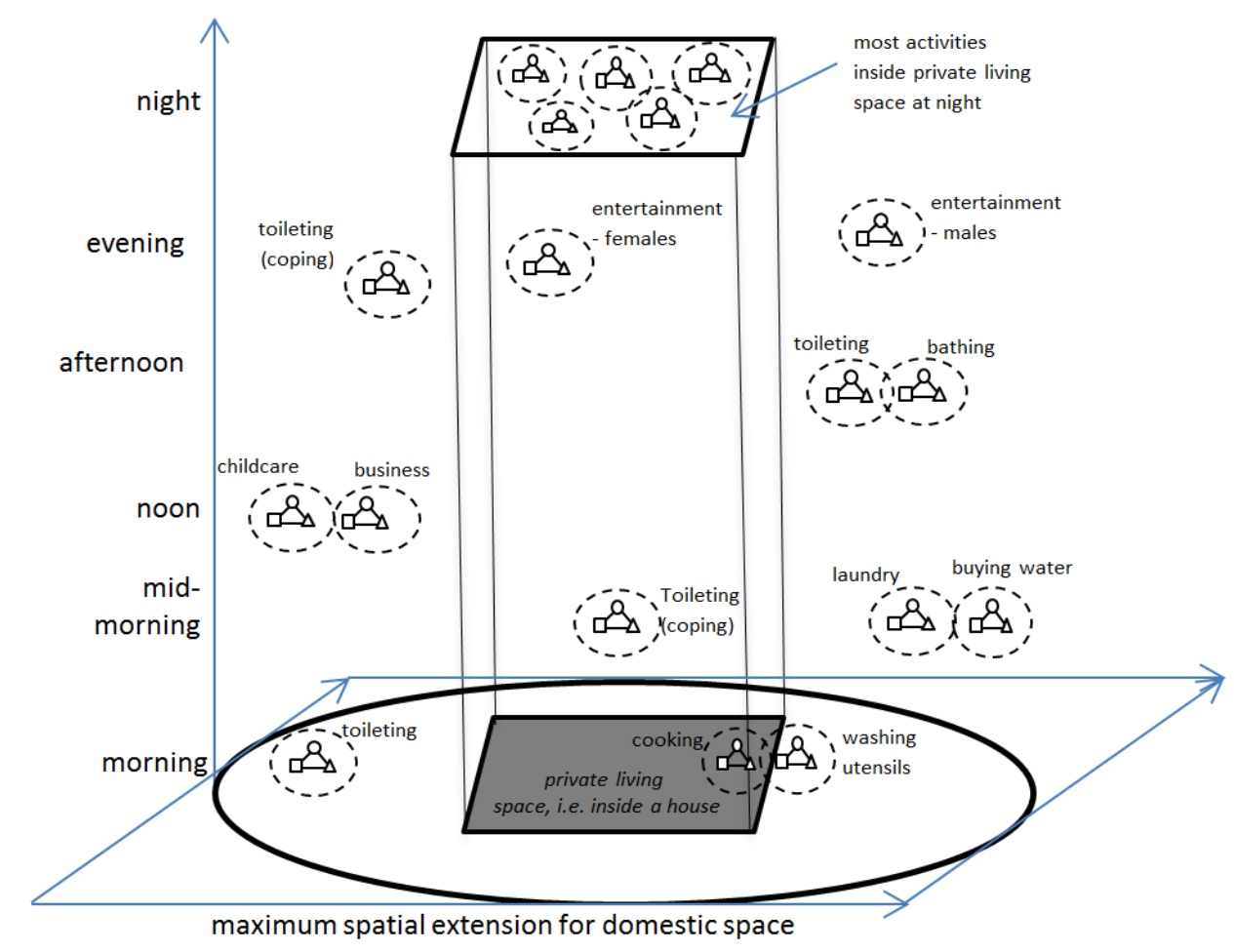

\subsection{Oscillating domestic spaces}

The analytical approach we propose enables an intricate and grounded analysis of practices. Domestic activities performed by inhabitants of informal settlements are constituted by elements and practice bundles arranged in time-space (Figure 4). We centre our analysis on a phenomenon we call the oscillating domestic space.

We define domestic space as the social and material expanse related to making a 'home' in which people engage in daily, which is manifested in interactions with other people and the material world in time and space. It can be analysed within the spatial extension for all domestic activities (Figure 4). The domestic space oscillates because there are continuous fluctuations in the practice preconditions, those being the immediate contextual factors that enable performance of the practice of interest. This means that we cannot assume that people have the effective opportunity-the capability-to perform desired practices. As we will show empirically, people may have the know-how involved in a practice, without having the means and freedom to make use of it. This lack of effective opportunity to engage in activities that contribute to people's well-being has been thoroughly discussed in the literature on 'capabilities' that builds primarily on the work by Amartya Sen (1993). We find that Sen's 'capability approach' provides valuable insight on how to conceptually understand the uncertain and unstable opportunities for performing practices in more precarious living, a consideration that we lack in current applications of practice theory. As we discuss further in section 2.2.1, the fluctuations in 
preconditions result in daily changes in the actual possibilities for accessing the fragmented and unreliable service options. The attention to time-space enables us to identify the fluctuations: we see daily and seasonal, regular and irregular, predictable and unpredictable, individual and structurallycaused changes in the practice preconditions.

In response to the way the preconditions are unreliable and unstable, inhabitants in informal settlements have to develop and maintain multiple practice arrangements in order to successfully perform a domestic task. Hence, the oscillating domestic space is our concept to capture these instabilities and to illustrate how individuals and groups rely on multiple but fragmented and unreliable service options to enable the performance of a practice. When the preferred option cannot be used due to a breakdown of linkages between practice preconditions (e.g. when a toilet cannot be used because of lack of water or electricity supply), people respond strategically by rearranging the possible linkages in time and space (e.g. by going to buy water elsewhere and bringing it to the toilet, therefore being allowed access). The person may also decide to use another toilet located father away or even open defecation. Deciding among several uncertain service options can expend considerable time and effort. We thus see how people develop strategies for different situations to manage every domestic activity. These response strategies are dynamic and contingent upon creativity and innovativeness, and explain why people develop a portfolio of alternative options across space and time. Response strategy as a concept does not signify the practices in themselves, but explains how the multiplicities of more or less appreciated practices are developed and become stabilised.

Figure 5 shows how the domestic spaces are extended (the shaded shapes) under specific preconditions for practice and the response strategies applied (double-pointed arrows). Hence, if the practice of 'going to the toilet' is composed of material elements such as a public toilet (the triangles), the know-how for using a facility, and the willingness to use it because it is not too far and it's clean enough, then the precondition for use is how all these factors shape the capability to access the toilet, such as: the toilet being open, the road being passable, the person having money to pay for access, and the service provider having water for flushing and hand washing. If the person lacks money on this occasion (a precondition), then the response strategy would be to go to another farther, and perhaps dirtier, option $\left(\mathrm{O}_{2}\right.$ instead of $\mathrm{O}_{1}$ in Figure 5$)$ where access is possible on credit. The shift leads to an aligning of a different set of practice elements in time and space. 
Oscillations of the domestic space $A$

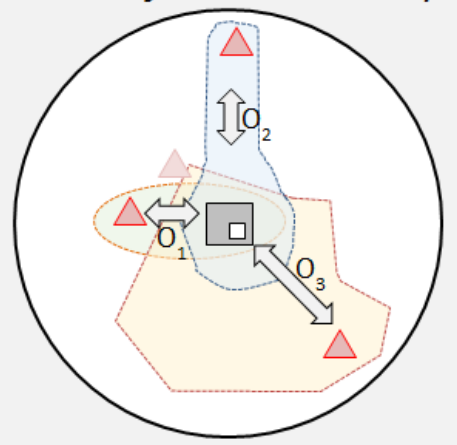

Oscillations of the domestic space A:

$\mathrm{O}_{1}$ : Nearest/favourable basic service option under undisturbed conditions

$\mathrm{O}_{2}$ : Alternative option when lacking money

$\mathrm{O}_{3}$ : A third possible alternative suitable for other preconditions

$\square$ : More stable response strategies (i.e. coping)

\section{Oscillations of the domestic space $B$}

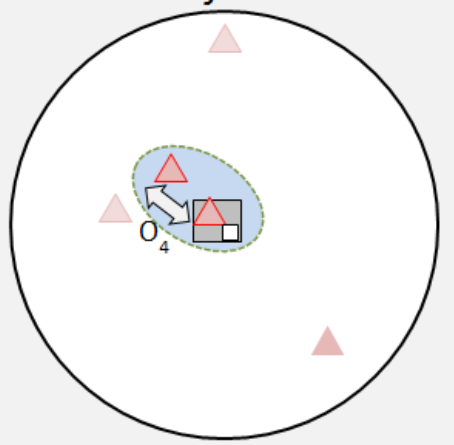

Maximum spatial extension for all domestic activities

Material artefact relevant for certain practices (e.g. water-point, toilets used)

Material artefacts which are completely inccessible (e.g. toilet one is excluded from using)

Minimal extension of domestic space. Private living space (i.e. plot; inside a house)

Extension of domestic space under preconditions and strategies of specific oscillations

$\Leftrightarrow$ Practice preconditions and response strategies shaping specific domestic space oscillations

The fluctuations in preconditions can originate either locally or at other scales and organisational levels, including processes and events that cannot be managed or controlled by local actors (users, service providers) and may even be difficult to manage by higher-level actors (utilities, governments). But they affect practice preconditions locally in important ways. These external factors include weather-seasonality, activities of Non-Governmental Organizations (NGOs), political tensions, social instabilities, economic meltdowns, practices of (informal) service providers, land tenure situations, norms and legislation shaping gender roles and women's access to resources, ethnicity, religion, and governments' activities and mandates in informal settlements. For example the lightly shaded triangles in Figure 5 represent material artefacts that are inaccessible by certain groups (i.e. because of social isolation based on ethnicity). We will highlight these external factors only to the extent that they are relevant for understanding oscillations in the domestic space of our empirical examples.

\subsubsection{Practice preconditions in informal settlements}

In line with Shove et al. (2012) we conceptualise practices as composed of three kinds of elements: materials, meanings, and competences, and suggest that the preconditions can be identified as reflecting these. The actual practice preconditions we specify are: (i) functionality of service infrastructures and artefacts (materiality), (ii) the individual and shared socio-cultural norms and values, and local institutions (meanings), and (iii) people's competences, personal characteristics and 
contingent abilities. The three preconditions together shape the situated capabilities of individuals to perform practices. Here we align with Sen who highlights three 'conversion factors' (environmental, social and personal factors) that together shape capabilities (Sen, 1993). These correspond well with practice elements as defined by practice theorists. However 'capability approaches' bring additional valuable insights on how to conceptually understand the uncertain and unstable opportunities for performing practices in more precarious living, a consideration that we lack in current applications of practice theory. We share Sen's critique about insufficiency of approaches that focus narrowly on real incomes and commodity-bundles in assessing capabilities, such as in welfare economics (Sen, 1993). We align with Sen in our attention to the multiplicity of factors that shape the kinds of practices that are possible based on both personal and contextual factors in the immediate living environment as well as the wider economic, social, political and institutional context. However, we do not adopt the full Capability Approach because our analytical objectives are more modest. We are aiming to understand preconditions for safe, affordable and reliable toileting practices rather than evaluating the capability of bodily health (i.e. see Robeyns (2005)). We are looking at a specific link in a bundle of practices related to one aspect of health and wellbeing. Second, practice theory as it has been developed in conjunction with sustainability transitions has a 'socio-technical perspective' which is missing in Capability Approaches. We specify further three practice preconditions for informal settlements:

First, the material functioning of basic service facilities is unreliable, thus access is often uncertain. There are a number of reasons for this including sub-standard constructions (i.e., small piping systems), very high numbers of users per water-point, bathroom or toilet, and insufficient supply of water and electricity (Kariuki and Schwartz, 2005; Satterthwaite et al., 2015). These factors lead to frequent non-functioning of basic services and ongoing infrastructural challenges facing providers (Otsuki, 2016; Thieme, 2017). Furthermore, basic service offerings that are located in public areas are open only during regular business hours and remain closed at night (Amnesty-International, 2010; O'Reilly, 2016). Important to note is the lack of formally regulated provision protocols so that services are made available only at the convenience of the service provider (Kariuki and Schwartz, 2005). These conditions mean users cannot predict availability, forcing them to look for alternative options every other time (Lawhon et al., 2017; Schwartz et al., 2015). Moreover, seasonal rainy conditions lead to deteriorated road infrastructure limiting movements of people and hence access.

Second, we acknowledge the significance of individual and shared socio-cultural norms and values, and local institutions in shaping practices. We therefore support the argument that introduction of new service offerings ought to be sensitive to formal and informal institutions ascribed to gender, age, class, ethnicity, religion etc. (Desai et al., 2015; Kulkarni, O’Reilly, \& Bhat, 2017; Lawhon et al., 2014; Truelove, 2011). However, we would like to highlight that in the contingencies of everyday life in poor 
communities where people struggle to maintain their well-being, the link between social norms and practices is not very stable. Inhabitants often engage in activities and practices that are risky or which they find unacceptable, shameful, and not in accordance with what is socio-culturally expected of them. So far, this aspect has not been adequately explored in connection with the introduction of innovations. For example, the innovations may be accepted despite being perceived as culturally unfit. We understand the socio-cultural preconditions for practices to be full of tensions between plural and diverging meanings and obligations in everyday life, resulting in hesitations between conforming with and bending the norms. We find support for this argument in the work of Stengers (2010), who emphasizes that "practices are not free from norms, but conformity is not the most important and does not determine the practice". We see that in our context, practices are thoughtful 'ways of doing' that form in response to challenging conditions that prevent the development of easy, comfortable routines and, instead, force people to stop, hesitate, and reflect on meanings, options and outcomes (Stengers, 2010). Norms still matter greatly, but we suggest that they play a more ambiguous role than previous discussions on practices characterized by routine and conformity have lead us to believe. This calls for more intricate approaches in understanding how individuals dynamically position their practices in relation to norms.

The third precondition is that individuals have to possess the competence, personal characteristics and contingent abilities that are necessary for accessing services or engaging in specific practices. Competence or know-how is important (as prescribed by practice theorists), but there are additional factors such as mental, bodily and physical characteristics and abilities as well as economic realities that facilitate or hinder access (based on insights from Capability Approaches). We see physiological needs as salient capability aspects for access to material resources and services. These include sickness, old age, menstrual days and pregnancy. They may reduce people's physical strength and mobility and thus reduce the extension of domestic spaces for performing domestic tasks. They may also influence demand for services, i.e. menstruation may increase the need of water, cleanliness, comfort and old age may require close distance. Lack of security, especially for women and girls who are vulnerable to sexual abuse, limit people's mobility and access to resources and services (Tilley et al., 2013). In the face of reduced mobility, greater need and security concerns, assistance from family and friends becomes important to enable access. Toileting is often an individual practice, but can also become a collective one under such circumstances. To gain access therefore, social relations become important. Further, we acknowledge that cities and informal settlements are generally very heterogeneous socially and culturally, creating a larger (compared to many rural settings) diversity of norms, values, beliefs, and perceived belongings (Gilbert, 2007). This creates diverse social spaces with variations of networks and overlapping hierarchies that influence possibilities for access. Additionally, informal settlements are typically inhabited by low-income communities that depend on irregular 
incomes. The majority hold a variety of casual employments, use savings and borrowings simultaneously, and save money using a mixture of formal and informal instruments (Collins et al., 2009). The irregular cash flow influences daily practices as most informal dwellers access water, bathrooms, and toilets based on pay-per-use offerings (Corburn and Hildebrand, 2015; WSUP, 2011). The intermittent incomes imply that people's financial abilities to manage daily domestic tasks are precarious and competing needs mean changing prioritizations. The third precondition therefore entails (in)capabilities in terms of know-how, physiological needs, security, social relations and economic abilities.

To summarize section 2.2.1, we see oscillation of domestic spaces to mean that informal dwellers have to manage domestic tasks in a complex entanglement of constantly changing states between: functioning and non-functioning services, socio-cultural norms and pressures to break these rules, and thirdly, changing capabilities in terms of know-how, physiological needs, security, social relations and economic abilities. These preconditions interplay to shape the effective opportunities for performing particular practices. As a result, domestic spaces are constantly changing, partly in foreseeable oscillating rhythms, but more importantly in rather unpredictable ways.

\subsubsection{Response strategies to precarious practice arrangements}

We identify four generic response strategies based on their institutional meaning and locus for action (Table 1). These are the strategic and innovative actions for rearranging the possible linkages between diverse practice preconditions in time and space to enable alternative access. Such actions highlight what people do when the preconditions for preferred options cannot align. Our categorization of response strategies by institutional meaning is inspired by our earlier argument that conformity does not determine practices. Rule breaking needs to be seen as important dimension to understanding practices. Categorizing based on 'locus for action' enables us to explain how socially undesirable practices could still remain prevalent in society.

Table 1: Response strategies are categorized based on institutional meanings and locus for action

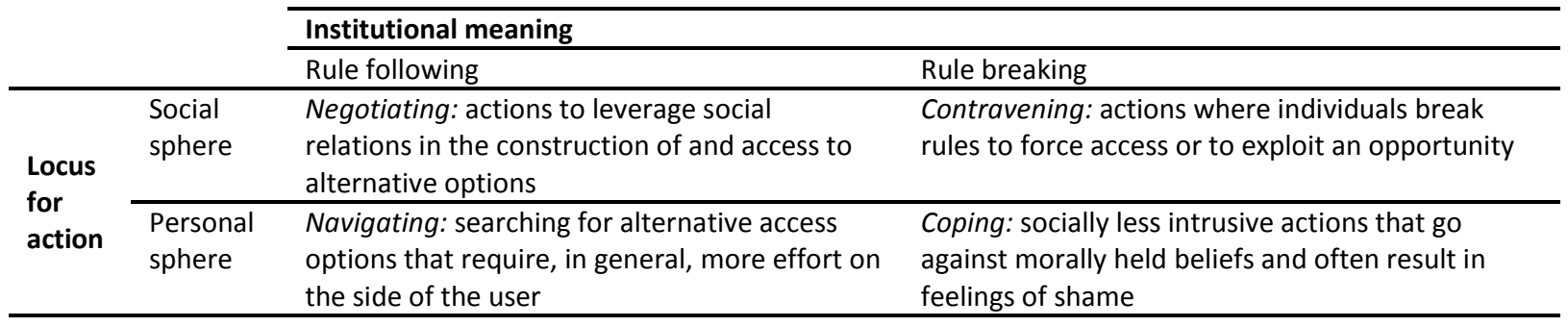

There are two proactive and socially congruent strategies that try to accommodate daily needs by finding alternative options to the preferred ones. We distinguish between those that can be adopted 
within personal spheres, that is navigating, and strategies for which social interactions become crucial, which we term negotiating. Navigating entails searching for alternative options to performing a practice and generally requires more effort on the part of the user. Examples include: only using facilities when at work or school or walking farther to find cheaper options. Negotiating encompasses actions to leverage social relations in the construction of and access to alternative options. An example is bargaining the terms of access in order to get cheaper access or to use on credit terms.

The other two strategies go against established rules and involve a higher risk of social sanctioning. Contravening encompasses those options where individuals break rules to force access or to exploit an opportunity. An example is when individuals break a water piping-system to access free-of-charge water, or when they trespass to access a public toilet. Coping represents a socially less intrusive set of options which entail practices that go against morally-held (public) beliefs and, if exposed, often result in feelings of shame. Coping is mostly done privately or secretly. Despite negative cultural connotations, coping is prevalent, i.e. everyone is doing it but few people acknowledge it publicly.

\section{Methodology}

We illustrate our analytical approach in the case study of access to sanitation in informal settlements in Nairobi, Kenya. Nairobi is a popular site for innovative interventions in the basic service sectors. A growing interest by the private sector to complement the struggling public utilities has led to several novel sanitation innovations being piloted in the city (Kalan, 2011; O'Keefe et al., 2015; van Welie et al., 2019), making sanitation in Nairobi an interesting case to study. We selected three villages ${ }^{5}$ in three informal settlements for a detailed study: 'Mathare-Bondeni', 'Kahawa-Soweto' and 'MukuruRorie'. The villages are selected based on the presence of small-scale sanitation innovations and new service offerings (Table 2).

Table 2: Data on historical and demographic profiles and on sanitation innovations and new services

\begin{tabular}{|c|c|c|c|}
\hline Settlement & $\begin{array}{l}\text { Year } \\
\text { established }\end{array}$ & Population* & $\begin{array}{l}\text { Innovation** } \\
\text { As of December } 2016\end{array}$ \\
\hline $\begin{array}{l}\text { Mathare- } \\
\text { Bondeni }\end{array}$ & $1920 s$ & $\begin{array}{l}\text { A village of 2,500 people (part of the } \\
\text { larger Mathare informal settlement of } \\
188,183 \text { inhabitants containing } 13 \\
\text { villages) }\end{array}$ & $\begin{array}{l}\text { 'Fresh Life' public container-based toilet. Introduced } \\
\text { but was not scaled } \\
\text { 'Banza' in-house container-based toilet. Introduced } \\
\text { but was not scaled }\end{array}$ \\
\hline $\begin{array}{l}\text { Kahawa- } \\
\text { Soweto }\end{array}$ & 1980s & $\begin{array}{l}3,000 \text { people (made up of the one } \\
\text { village) }\end{array}$ & $\begin{array}{l}\text { Newly introduced shared Water-Closet toilets. Five of } \\
\text { the seven toilets not in use after more than } 5 \text { years }\end{array}$ \\
\hline $\begin{array}{l}\text { Mukuru- } \\
\text { Rorie }\end{array}$ & 1998 & $\begin{array}{l}\text { A village of 5,832 people (part of the } \\
\text { larger Mukuru informal settlement of } \\
100,000 \text { inhabitants containing } 11 \\
\text { villages) }\end{array}$ & $\begin{array}{l}\text { 'Jitegemee' in-house container-based toilet. There was } \\
\text { initial acceptance but very low levels of embedding. } \\
\text { 'Fresh Life' public container-based toilet successfully } \\
\text { introduced but struggling with scaling }\end{array}$ \\
\hline
\end{tabular}

* Source: Karanja and Makau (2012)

\footnotetext{
${ }^{5}$ Our analytical level is based on the conventional practice in Kenya that innovations are often introduced to community groups based on lowest administrative structures in informal settlements-the villages.
} 

** Only 'Jitegemee' will be elaborated in more detail in the results section to exemplify the heuristic value of our analytical
approach. Experiences with the other innovations and new offerings will only sporadically be exemplified.

The first author collected data in Nairobi in five-month period: February and March 2016 and October to December 2016. In order to investigate sanitation practices, we needed multiple types of data. The first data-set investigated women's everyday domestic tasks. We focus on the women because they are primarily responsible for domestic tasks in the informal settlements of Nairobi and are considered to be disproportionately affected by sanitation challenges. The respondents are 32 women who were purposively selected with the help of a local contact person in the three villages. Our initial approach was to select respondents to represent use-experiences with specific toilet-types (e.g. public by NGO, public by social enterprises, shared, private-sewered, private-onsite, new offerings or other). However, the categories could not be precisely used as most residents tended to use more than one option in the course of a day. Therefore, we shifted towards getting a complete picture of all possible alternatives used by the interviewed respondents and possible within the study areas. Among the interviewed women, five were beneficiaries of a novel container-based toilet known as 'Jitegemee' which is highlighted in the result section. Investigations focused on how they interact with persons and (new) artefacts in order to successfully manage domestic tasks in time and space, and what this means for them personally and for their livelihoods. Domestic tasks include, but are not limited to, cooking, washing clothes, cleaning utensils, childcare, fetching water from a water kiosk, bathing, relaxing after finishing domestic chores, and toileting. For the informal settlements context, we consider toileting a domestic task as it requires time and mobility to reach the toilet artefacts, it competes with other domestic tasks for resources (i.e. time, money), and daily negotiations and navigating are required to gain access. We used semi-structured interview schedules as the main form of inquiry. Interactions with each interview respondent lasted 65 minutes on average. We followed the interview schedule but the interactions were less structured sometimes allowing breaks, changing the order of questions or incorporating transect walks with the respondents. This allowed them to freely share as much as they wished in a form they were comfortable with. As sanitation is sometimes perceived as a shameful topic to openly discuss, creating a flexible interviewing environment enabled respondents to open up and to give more personal views. Interviews were complemented with observations of where, how and when the domestic tasks are carried out. Also complementing the interviews were two initial exploratory Focus Group Discussions (FGDs) with women during the first fieldwork, and three for validation at the end of the second fieldwork. The first author conducted the interviews in the local language, Kiswahili. All these interviews were conducted in the informal settlements, mostly in the homes of the respondents. As such, the first author also spent considerable time in the villages observing and experiencing everyday situations and conditions. The interviews were recorded and later transcribed then translated into English. 
A second data-set for additional perspectives of the three villages included inquiries with 22 NGO representatives, 3 community health extension officers, 9 local administrative leaders and 3 male residents. Our primary focus was on women. However, we sought the perspectives of the male inhabitants in order to corroborate some of the gender-related responses that arose during the interviews. The full list of anonymised interview respondents is presented in Appendix 1. The respondents are referred in the results section with code names (e.g. MB1 for Mathare-Bondeni respondent 1, FGD1 for Focus Group Discussion 1, ...).

The interviews and notes were coded by means of MaxQDA-12 software. The coding process led to an extensive coding scheme covering domestic activities, sanitation activities, internal and external factors influencing access, practice preconditions, response strategies and experiences with new service offerings. This data was coded using an iterative process based on the original practice theory dimensions and with additional dimensions we derived from the data that helped to define our concept of oscillating domestic spaces. The second and third authors participated in analysis of data, resulting in joint reflection on and discussion about the interpretation of findings.

Before we go to the results, we explain the choice to present the stories of three women among the 32 interviewed and how we practically applied our analytical framework. Presenting the three stories in a descriptive way is intended to provide the reader with a detailed picture and understanding of the context and preconditions for performing practices. To practically apply our analytical framework, we start by mapping the physical outline of the spatial extension for all domestic activities. We use the family house as the reference point ${ }^{6}$; hence the family house represents the minimum domestic space extension. In Nairobi's informal settlements, however, various domestic tasks are undertaken outside-in front of the house, in the yard, or in public spaces such as next to the street, fields, pathways and at service-points. Small housing units, often one or two-roomed family houses, leave little space for domestic tasks. Moreover for convenience, householders prefer to attend to domestic tasks at service-points; i.e. laundry at the yard-taps and water kiosks rather than carrying water to the house, a tedious and cumbersome task. We, then, can spatially and temporally relate the defined domestic space to the recurrent practice of toileting.

\footnotetext{
${ }^{6}$ This makes our analysis comparable with previous socio-technical studies where domestic living spaces are conceptualized. Examples include: Khalid, R., Sunikka-Blank, M., 2017. Homely social practices, uncanny electricity demands: Class, culture and material dynamics in Pakistan. Energy Research \& Social Science 34, 122-131., Eon, C., Breadsell, J.K., Morrison, G.M., Byrne, J., 2017. The home as a system of practice and its implications for energy and water metabolism. Sustainable Production and Consumption., and Strengers, Y., 2013. Smart energy technologies in everyday life: Smart Utopia? Springer.
} 


\section{Results}

In section 4.1, we describe the everyday life of the three women and how they manoeuvre access to toilets as they go about other domestic activities in time and space. We highlight 'in brackets' how the data corresponds to analytical categories. Because the stories of the three women do not capture all the findings from our data in terms of plurality of situations, with varying preconditions and response strategies, we make a summary in Section 4.2 that provides some generalizations based on all 32 interviews. Section 4.3 exemplifies the heuristic value of the analytical approach using the case of 'Jitegemee', a new container-based toilet which is designed like a bucket and consisting of an airtight lid.

We visualise the domestic oscillations of the three women in Figure 6 on the basis of empirical data, and label these as Case 1, Case 2, and Case 3. The illustrations emerge as representative examples from our empirical material and are thus context-specific to Nairobi's informal settlements. Case 1: Clara is a woman with several possible alternatives within the maximum extension of domestic spaces but she lacks an in-house option. Case 2, Hanna, is a woman with an accessible in-house or on-plot option. Case 3, Grace, is a woman with several toilet artefacts within the maximum spatial extension but the preconditions do not allow access at any given time.

Figure 6: Illustrations of oscillations in the domestic spaces of three individuals who have similar maximum domestic space extension

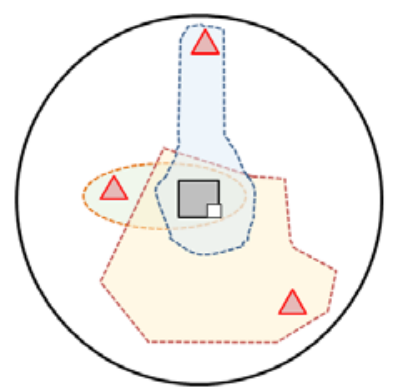

Case 1: Clara has several toilets within the maximum domestic space extension

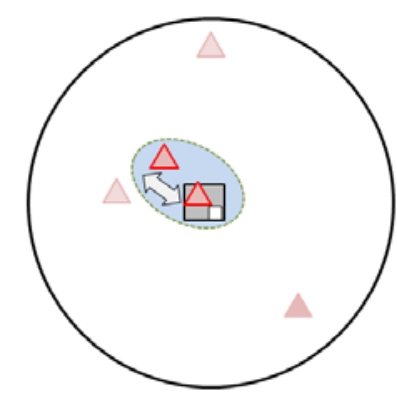

Case 2: Hanna has a toilet within the minimum domestic space extension (in-house)

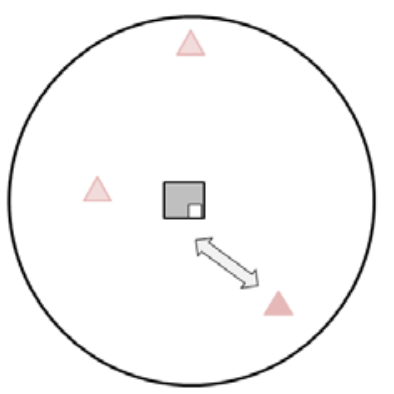

Case 3: several toilet artefacts available within the maximum domestic space extension but none is accessible to Grace

\subsection{The stories of three women and their activities in domestic space}

\section{Case 1: Clara}

The 36 years old Clara has several possible toilet alternatives within the maximum extension of her domestic space but lacks an in-house option.

Clara lives in Mukuru-Rorie in a two-roomed house together with her husband and 3 children. Clara is dependent on irregular casual jobs for an income; among them is a weekly journey to a smaller town 
about 100 kilometres from Nairobi to sell second-hand clothes. Clara's husband works in an industry nearby on a temporary and casual basis.

On a regular day, she goes to a middle-class neighbourhood nearby where she waits outside the entrance for a potential domestic job for the day. She comes home empty handed more often than she manages to get a job (income uncertainties). Clara gets up at 6am, and twice a week she goes to a large second-hand clothing market downtown to buy her business stock. She performs regular domestic tasks everyday like purchasing water and cleaning utensils and clothes from a nearby kiosk (spatial extension). She finishes her domestic tasks at 10am, after which she visits friends in their houses or goes out to look for any casual jobs (navigating for an income).

"Visiting friends is nice. You get to know what is going on in the village (...) that's how you easily get involved in community projects, (...) maybe an NGO is having a workshop and you get a little money"

There are about 3 public toilets Clara and her family can access within her maximum spatial extension. She does not have access to a private toilet. A public toilet about 20 meters from her house is indefinitely not in operation due to internal group management problems (unreliable artefacts and infrastructures). Other alternative public toilets within her domestic space are, respectively, 20 and 50 meters away. One of them is a 'Fresh Life' public toilet, a new option provided by a social enterprise. Whenever Clara has money, she prefers to use the 'Fresh Life' which she finds very clean and smells fresh. But when she does not have money or late at night when the 'Fresh Life' is closed (time/space oscillation), she will use other options which she may consider very dirty (oscillations based on time/space, money, and service-hours; navigating). At night when Clara cannot go outside (time/space oscillations relating to (in)security), she responds to the limitation by using the 'flying toilet' strategy (coping).

At night? Which choice is there? You just use 'flying toilet' (...) sometimes you find someone has dropped it outside your door. (...) if you see a nice shinny plastic bag lying on the street, do not trust it!"

Clara and the family have a routine to visit the toilet right before it closes at 10pm (navigating). This way, there is a possibility of getting through the night without needing a toilet.

Clara was one of the beneficiaries of an innovative in-house container-based toilet named 'Jitegemee', about 2 years earlier. She stopped using it and stored it away when her children started attending boarding school. She found it to be useful only for the children (socio-cultural meaning). For herself, she preferred to find ways to 'navigate' access by asking friends, going to the local bar, or just 'holding' until morning (navigating). For her, the new task of disposing the faecal waste at a toilet and then cleaning the container was unpleasant, time consuming and also consumed too much soap and water. 
Nonetheless, she uses 'Jitegemee' whenever she is unwell ((in)capabilities related to physiological needs). Also, Clara still uses 'Jitegemee' despite the negative socio-cultural perception attached to it (bending socio-cultural norms), but her husband would never use it (socio-cultural meaning).

"My husband said he will not use it. Men here refused to use it (...) they said that it is a 'potty' for children (...) you know the houses are small so my husband cannot use it here and the children are here. (...) even in the bathroom he cannot use it there, he prefers to walk around even at night to find an option outside (gender-specific extension of domestic spaces; navigating)"

"When 'Jitegemee' was introduced we (the women) were not shy to use it. We didn't have other options, toilets were very far away. Now that we have more public options we question and laugh at ourselves really what this is that we used" (bending socio-cultural norms)

For Clara, knowing people who manage toilets is very important as one is able to use the services on credit when without money. Previously, her friend used to operate a public toilet. Her family would use this specific one whenever possible (access based on social relations).

"It was nice because my children would go to this toilet whenever I was not home to provide them money for the toilet payment. I would later pay this friend the accumulated amount" (navigating).

Increasing insecurity in the neighbourhood often limits Clara's movement. Interestingly, insecurity conditions fluctuate. When insecurity becomes unbearable, community members often mobilize themselves to deal with the suspected offenders, who are sometimes local community members.

"After such an operation, the community is much safer but after some time we start fearing again (...) right after those operations you can walk around even in the night (and go to the toilet) and no one will touch you" (time/seasonal oscillation related to (in)security).

The security situation disproportionately affects women and girls. Clara's 16 year-old daughter is more vulnerable in public spaces, and her mother worries about issues of sexual harassment (gender/agerelated differentiation in oscillations). Clara navigates this situation by making sure she accompanies her daughter to the toilet when it gets dark (navigating).

Clara's husband prefers to use the toilets at his workplace every morning to avoid the morning hassle of looking for a functioning toilet (navigating). This saves costs as well. In the evening when he comes back from work, it is common for male adults to spend time at the local social hall to follow the news on TV, where they get free-of-charge toilet access (gender-specific extension of domestic space; navigating). Clara's role as a homemaker means she deals more with the everyday access challenges. As a woman, she is also expected to meet her toileting needs in more private areas compared to male counterparts (gender-related cultural constraints). Furthermore, to meet her menstrual needs, Clara would require more toilet visits (temporal oscillation based on physiology). Clara thinks these 
differences are the reasons why toilet management groups are populated by women. "It is an important way to survive for the women" (navigating). Clara's engagement in the past in a toilet management group helped her to expand access opportunities as she became a trusted person and thus could use toilets at a cheaper rate or even cost-free (access based on social relations; navigating).

\section{Case 2: Hanna}

Hanna, 49 years old, has an accessible toilet within a minimum domestic space extension.

Hanna lives with her husband and 8 year-old grandchild in a two-room apartment block in MathareBondeni. Hanna has been selling peanuts for a living on the main street within her neighbourhood for the past seven years. Hanna's husband is a mason worker, meaning his job takes him out of town for weeks, followed by an unemployment period until he finds another masonry contract (income uncertainties). In this case, Hanna is happy that her stable but low-income business sustains the family during her husband's unemployment periods.

Hanna often wakes up at $6 a m$, prepares her grandchild for school, then carries out domestic tasks. She does most of these tasks inside her apartment (minimum domestic space). Mid-morning she roasts the peanuts before subsequently spending all afternoon selling. Hanna has an in-house pour-flush and sewer-connected toilet. Compared to her previous house in the same area, where she had only offplot public toilet options, life is less difficult.

"Even if we got used to the previous life, now I see that I had to do a lot of things, sometimes you have to carry your own water to the toilet, sometimes you have to walk so far away (unreliable artefacts and infrastructures; navigating). When we didn't have money to pay for the toilet we would go down to the river to defecate when it was dark (time/space oscillation based on economic precarity; coping) (...) the toilets were also very dirty, (...) it was very hard especially in the beginning in 1986 when I had just arrived here from my rural home".

The cost for maintaining the in-house toilet is included in the rent therefore she does not have to make any daily payments for access. Hanna does most of her domestic tasks inside her house because it is spacious and she has an in-house water connection. However, water shortages occur often. Hanna has to rely on water kiosk services often (unreliable artefacts and infrastructures; navigating). She sometimes cleans clothes at the water kiosk. Over the seven years she has lived in the apartment, Hanna has not experienced any problems with the toilet and therefore she has never required alternative options. And because her small-scale business is only a few meters from her apartment, she prefers to walk back home during the day whenever she requires toilet access. Interestingly, one of her daughters who lives nearby (MB8) often uses Hanna's toilet (access based on social relations; navigating) to save on costs from public toilet use. 
Hanna is aware that her in-house toilet is connected to a broken sewer that leads to the local stream nearby, and which by this contributes to the unhealthy and unhygienic environment where she must spend most of her day (know-how about health and hygiene). However, she lacks capacity on her own to improve the sewerage problem (external condition that contribute to oscillations).

\section{Case 3: Grace}

For Grace, 40 years old, there exist several toilet artefacts within maximum domestic space extension, but she can never access them (or only has access on very few occasions as a response strategy).

Grace is a widow who lives with her 6 children in a one-room house. Grace is the sole breadwinner of her family and depends on irregular casual jobs for an income. Having a large family and relying on irregular jobs means that Grace and her family live 'from hand to mouth' (income unreliabilities).

"Yesterday when I woke up, I had a little sugar that had remained from the previous day, so I made breakfast for my children (...), lunch I didn't have anything..., whenever I am successful (to make some money during the course of the day) I stock up for two or three days - I buy sugar, maize flour, and the firewood that is lying outside the house. We can then have a meal and sleep..., the days to follow God will provide".

On a regular day, Grace wakes up at 5:30am to prepare breakfast for her children. The children will help each other get dressed, have breakfast and within an hour head out to a nearby school. A twoyear-old child remains at home and accompanies Grace all day. Grace then tidies her one-roomed house, takes the dishes to wash along a public path, and once every two days she washes the dirty clothes that have accumulated. She washes the clothes at a water-point about 100 meters from the house (spatial extension). When Grace finishes her domestic tasks between 9am and 11am, she visits friends and neighbours to check if she can get a job for the day (navigating for an income).

"There are no jobs; even now I was just about to leave the house to 'hustle'. I just arrived back from a job I was given to clean the church. Now I want to go to the village-centre and see if I will meet someone else who can have a job for me (...) perhaps a farming job, as it is raining right now (...), whatever job comes I will take".

Grace and her family are not part of an agreement to use shared toilets that are found close to her house (limitation on social relations). She does not own a private toilet. The closest public toilet to her house is about 500 meters away. Grace considers the toilet too far away and so she does not use the option.

"We do not have access to a toilet (...), we just try and ask around from neighbours (access based on social relations; navigating), I ask one neighbour today, another tomorrow, all my children do the same, it becomes hectic for us and the neighbours (limitations on social relations), so for my children when time allows (i.e. at night - time/space oscillation) I let them 
use plastic bags (coping) which we dispose into the solid waste (...), all other private and shared toilets, including that of the church nearby, are 'padlocked' (...) even for a pay they will not allow non-congregants (limitation on social relations). The only one that we are able to use for a pay is very far (...), we cannot go all the way there to use the public toilet, it is just too far (...), this whole area does not have a public toilet (...) at night you would not want to wake up your neighbours (time/space oscillation) so we do 'what we can' (coping)."

For Grace, if there was a public toilet within her domestic space extension, she would regard herself as having some access although she states that she still might not always be able to afford daily access for her entire family (economic uncertainty). Also, considering the demanding obligation to take care of her large family, Grace is not in a position to invest in sanitation by buying a toilet, building a toilet or getting membership to a shared toilet group. Furthermore, lack of space to construct and being excluded because she belongs to a minority ethnic group limits her access possibilities (limitations based on economic means or social relations).

"So where can I build and this room is so small even to live with my children? There is no space. (Also) I have tried to speak with neighbours to collectively get space for a toilet (negotiating), but my neighbours are of a different ethnicity, they will not want to invest with me."

\subsection{Relating the stories of the three women to the complete set of interviews}

As the stories of the three women cannot capture all the findings from our data in terms of plurality of situations, preconditions, toileting options and response strategies, we now relate their experiences to those of the other 29 respondents.

We can see that daily precarity in practice preconditions is common-place for all three cases and that gaining and maintaining access depends largely on how they deal with the fluctuations by applying diverse response strategies. Despite the three cases representing what we see as different positions on a spectrum, (i.e. Clara has many options, Hanna has one main option and Grace has no regular option), we see that Clara and Hanna are involved in frequent situations when preferred options fail and alternatives are sought. For Grace, some form of access is acquired despite lacking connection to any toilet option. These are indications of fluctuating preconditions for practices, resulting in a multiplicity of more or less accessible and appreciated options.

For case 1 , which represents a situation with a multiplicity of alternatives, there are many fluctuations and aligning preconditions to enable a practice requires a lot of effort and even luck. Clara therefore has to use coping, navigating and negotiating strategies. From the other 29 interview respondents, 
some $^{7}$ that can be categorized as having spatial conditions similar to Clara engaged in the following response strategies: (i) Negotiate: request for cheaper or on-credit access, group visits to toilets, and use on credit. (ii) Navigate: use options managed by women, routinized toilet visits, use toilets at work, walk further to cheaper/cleaner toilets, temporary use of culturally unfit artefacts (i.e. in-house container-based toilets), use friend's toilet, engaging in toilet management groups. Sometimes when several preconditions allow and align, people get the opportunity to use the more convenient, the cleaner or their most socio-culturally desired options. (iii) Cope: open defecation, flying toilet, dumping faecal waste from container-based toilets into drainages. (iv) Contravene: forced public toilet access by breaking doors, using more than paid for.

For Case 2, despite Hanna having a toilet at home, it depends on external infrastructures to function, i.e. when water is unavailable for flushing and she must find an alternative source in order to maintain hygiene. Other interview respondents who like Hanna have an on-plot option gave situations of access precarities when response strategies have to be used. For example, shared on-plot toilet users negotiate the maintenance of toilet facilities among themselves. An illustrative example is that of one respondent who has taken over everyday maintenance of a number of shared toilets, and in return obtains privileged private access to one (MR1). Response strategies mentioned in this category include: (i) Negotiate: get exclusive access in exchange for cleaning services, use a friend's toilet when their septic/pit toilets require faecal waste emptying service. (ii) Navigate: use public toilet when running domestic errands away from the house, choosing to use less preferred option (e.g. a container-based toilet) when regular option is not functioning, use kitchen waste-water for flushing and incremental improvement of existing toilets. Example of an incremental improvement is changing from a pit to septic-tank toilet or connecting to a sewer over time (iii) Cope: open defecation and flying toilet when on-plot pit latrine needs faecal waste emptying and cannot be used.

The Case 3 provided a useful illustration of how social (in)capabilities enable or limit access. For Grace, despite the presence of several toilets artefacts within her domestic space, she could not access any of them because of her social belonging to a marginalised ethnic group or being a non-congregant of a nearby church and therefore being excluded. The other 29 interviews include some respondents with similarly limited access. Stories of the development, over time, of common locations where open defecation is done-so called 'hotspots' - were prominent among these respondents. The women accompany each other to these open locations. This way, despite it being a non-desired response strategy involving shame, they make it into a structured practice of going together (FGDs 1 \& 3 ). This illustrates how response strategies may change norms and result in the emergence of new practices

\footnotetext{
${ }^{7}$ We refrain from giving precise numbers because we see the 29 women to be evenly positioned along a spectrum of domestic space oscillation dynamics. Further, our interest is to show similarities at different points of the spectrum rather than pointing out differences.
} 
over time. Open defecation can under these circumstances be categorized as a collective practice with distinct recognizable elements. People have an understanding - the know-how-about how, where and under what circumstances open defecation is done (FGD 3). The same phenomenon is illustrated by the 'flying toilet' whereby many informal dwellers have shared understanding of how to undertake the strategy. The response strategies mentioned by other respondents with similar experiences as Grace includes: (i) Navigate: use friend's toilet, use at work, and accompany each other to open defecation hotspots. (ii) Cope: establish open defecation 'hotspots', use 'flying toilets'.

Two general observations, related to response strategies, are worth mentioning. First, response strategies can become stabilized and transform into long-term strategies or permanent solutions. For example, people negotiate with neighbours to invest together to construct new toilets. They also negotiate to gain membership to a shared/public toilet group, and as well negotiate with service providers for flat-rate monthly payments by families instead of the regular pay-per-use. Second, there are benefits from response strategies that spill (beyond only toileting) over to other domestic activitydomains. For example, joining a toilet management group enables other joint activities like savings, which contribute to 'earning a living' (MB3, NGO rep 1) .

\subsection{Implications of the oscillations in domestic spaces on the embedding of 'Jitegemee' container-based toilet}

To exemplify the heuristic value of our analytical approach, we use the case of the 'Jitegemee' container-based toilet. It is designed like a bucket and consisting an airtight lid. 'Jitegemee' was introduced as an in-house family solution in two informal settlements in Nairobi in 2011. The 'Jitegemee' was envisioned by the innovators and providers as an environmentally-superior option to replace open defecation and other unhygienic faecal disposal practices, and also a more decent alternative enabling toileting in the privacy and safety of homes (McSorley, 2012). The users were required to take the container to a public toilet where they would pay to dispose the waste. 'Jitegemee' was designed by engineers from an international NGO in 2009, and in 2011 a user-needs survey was conducted before its introduction (McSorley, 2012; Mohanty, 2018). The approach was novel as existing approaches at the time only focused on constructing permanent off-plot public toilets. The NGO piloted 60 'Jitegemee' units, giving them to families in Mukuru-Rorie. Based on interviews with the beneficiaries, there was initial acceptance but very low degree of embedding in the long-term. Of the five interview respondents with experience of 'Jitegemee', none perceived it an adequate single option. Two respondents (MR2; MR3) used it only on very few occasions and the other three (MR10; MR11; Case 1) had completely abandoned it - keeping it stored away or re-purposing it as cleaning and storage containers. 
Initially, when the 'Jitegemee' was offered, the beneficiaries were very enthusiastic about it and eager to use it. They explained in a group discussion (FDG 4) that they were even confident to show themselves as users in a national TV program that featured the innovation. However, over time, as other conventional services became available (conveniently located public and shared toilets), they stopped using 'Jitegemee'. An interview respondent (Case 1) and her neighbours only later questioned and laughed at the idea that they had accepted and used it for a while, despite perceiving it as not conforming to their socio-cultural norms. This example shows why it is problematic to assume that practices are based on conformity and neatly-mirrored norms, values or beliefs. There is a more ambiguous relation between what people do and what they see as appropriate, desired, or good, especially when conditions do not permit consistent options. Sometimes, novel service-offerings are accepted even though they are perceived as socio-culturally unfit or involve shame.

Secondly, the 'Jitegemee' service option was made useful as an 'add-on' to create a more diverse portfolio of alternatives rather than as a permanent replacement of previous practices (MR2, MR3, and FGD 2). 'Jitegemee' was not entirely reliable and fitting for all sorts of daily constellations. In addition, the respondents perceived a complete shift to a new option as risky. The majority still maintained the seemingly inferior options that have proved meaningful and useful in specific precarious situations. Households used 'Jitegemee' in specific but limited situations-as a full-time solution for children and as an emergency option for female adults on certain occasions. To the knowledge of the respondents, men refused to use 'Jitegemee' (MR2; Case 1). The different ways 'Jitegemee' was appropriated by household members did not correspond to the expectations of providers to become a 'family solution'. For the women who used 'Jitegemee' occasionally, they still reported other situations when they were still forced to opt for open defecation (MR2, MR3, and FGD 2). The preconditions for making use of 'Jitegemee' do not always align with each other. For example, a female household member is not able to use it in the evening when the entire family is sitting inside the one-roomed house - she may thus resort to open defecation outside (CHEO 1). So even if 'Jitegemee' is available in the home, its use depends on alignment of the artefact with other practice preconditions. Therefore, the process of embedding new services or artefacts should not only be understood as providing users with the superior artefact, but also as the provision of an additional option that often demands thoughtful re-arrangements of time-space, social and economic patterns in the oscillating domestic spaces.

Thirdly, interview respondents indicated that the introduction of the 'Jitegemee' may also have increased the practice of dumping faecal waste into open drainage. The inability by users to adapt the faecal waste handling system for 'Jitegemee' undermined the idea of an environmentally friendly alternative. Safe disposal required the unpleasant tasks, by users, of taking the container across the neighbourhood to a disposal-point and cleaning it afterwards. Also, their precarious incomes did not 
allow the users to consistently afford the daily payments for disposal services. Therefore, users were forced to frequently resort to unsafe dumping to avoid shaming and whenever they lacked money (MR5; MR9: MR10).

\section{Consequences for research and practice}

The lack of attention to contextual conditions and users' daily realities can explain why seemingly superior innovative options fail to successfully substitute existing undesirable practices like open defecation in Nairobi's informal settlements. We have been able to make sense of the complexity of everyday life in informal settlements and how embedding of new service offerings works by means of a socio-technical, context-sensitive, and actor-centred approach - namely the oscillating domestic spaces. We suggest that a fruitful approach to introducing an innovation would be to consider the process as a situation that pushes users to reflect on a wide range of constraints, opportunities, and priorities in the entire domestic space. As such, new service offerings should be implemented with a well-informed picture of contextual conditions for practices. This view is actually shared with the innovators behind 'Jitegemee' who consider the initial introduction to be a pilot R\&D phase. They are taking lessons from the user-experiences to further develop container-based solutions that would be appropriate for different informal settlements in Nairobi ${ }^{8}$.

"Me as an engineer designing a toilet, with no community consultation or engagement, was so obviously, a limiting factor and a shortfall. Perhaps fortunately, despite this, it wasn't a failure. This project was an outstanding example of a strong R\&D with lot of useful learning." (Mohanty, 2018)

Further, we suggest that when innovators undertake a market survey, the inquiry should result in a dialogue on the degree of complexity, competing needs and obligations, and the range of considerations for users when they make actual choices.

Our study also shows that in informal settlements users cannot be easily categorized in binaries like individuals 'with specific access types' or those 'without and without access'. This is because under the quickly changing and precarious circumstances, users often depend on multiple types of access options in the course of a day. We suggest that because of this service fragmentation and because of ambiguity in social spaces, one finds a plethora of finely splintered and highly dynamic dispositions among inhabitants instead of rather well-segmented and well-behaved 'markets'. Categorization is, however, often done in innovation management in order to identify specific market segments, such as

\footnotetext{
8 'Jitegemee' is collaborating with 'Fresh Life' to develop further container-based solutions in Nairobi in terms of design, functional waste management systems and scaling opportunities. See Oxfam, 2016. Container based sanitation could solve the world's toilet problems, Oxfam Policy \& Practice Blog. Oxfam.
} 
those that lack technical facilities, those whose values align with the new service offering, and those who have a critical ability to pay. Market segmenting of this kind often rests upon the assumption of stable practice preconditions. This finding also supports our critic of the linear and mechanistic 'sanitation ladder' which is used in estimating access levels in the Sustainable Development Goals. The complex overlap in the utilization of different access levels requires careful considerations. Also in consideration of our critic of insufficient accounting for precarities, we suggest that an estimation of 'the population using improved sanitation sources which are available when needed' can be added into the list of SDG sanitation indicators. Current indicators maintain the assumption of facilities being either permanently available or absent ${ }^{9}$.

In view of our findings, we derive four important lessons on how innovations can be more successfully embedded. The lessons relate to: (i) users playing proactive embedding role, (ii) 'acceptance' and 'embedding' as distinct processes, (iii) successful embedding is dependent on broader material and social structures, and (iv) the need to innovate together with people who are knowledgeable about application contexts.

First, users are not passive adopters of innovations but conscious, proactive and often capable managers of their livelihoods in quickly changing and resource constrained contexts. In this sense, a preference by users for a diverse portfolio of alternatives and a partial uptake should not to be perceived as a failure. The desired outcome of innovators to have a superior offering quickly substituting an inferior represent the passive view on user agency. Users will often experiment and proactively embed an innovation in a way that best fits to and supports their entire domestic practices and livelihoods opportunities. Therefore, users may often experiment with a new option but cautiously still engaging in old (sometimes inferior) practices that have proved meaningful in the past. They are cautious to see that the new offering can deal with all sorts of conditions and oscillations. In some cases, the perceived advantage of an innovation may be outweighed by the range of competing obligations, priorities, and handling of logistics and risks. Further, not only does substitution require that users make considerable effort and expend resources, it may also be impossible due to practice preconditions that are influenced by challenging factors that are beyond the user's control (such as lack of infrastructures-roads, water, housing and electricity). The innovation, therefore, may be found to be appropriate just under specific situations of oscillating domestic spaces, thus leading to an incremental improvement or being appropriated in a different way from the vision of the innovator. At an aggregate level, innovators should keep in mind that the proactive appropriation processes by users can also cumulatively reshape societal practices, values and norms or further reproduce the multiple and fragmented nature of service provision options. An example on reshaping societal practices is

\footnotetext{
${ }^{9}$ For a comprehensive list of the indicators (i.e. the 10 ratios), refer to WHO/UNICEF, March 2018. JMP Methodology 2017: Update and SDG baselines. WHO/UNICEF.
} 
when 'response strategies' become stable practices. The continued perception by users that any new service offering could best function as 'add-ons' exemplifies the further reproduction of fragmented service options.

Second, 'acceptance' and 'embedding' have to be seen as distinct innovation phases. Acceptance is when users attribute positive meaning to a novel service option. This can be acquired even before having any practical experience with the innovation (i.e. convincing potential users through an education program that 'Jitegemee' is an environmentally superior and a convenient alternative). The attribution of positive meaning, however, should not be seen as sufficient indicator for successful embedding. Embedding only happens when users actually integrate the novel option into their oscillating domestic space such that they are satisfied with everyday efficiency and convenience. Innovators and service providers could still facilitate the embedding process, for example by making practice preconditions more stable and reliable (e.g. providing a consistent disposal location for wastes from 'Jitegemee', and adapting the logistics for disposal to fit with other domestic activities).

The third lesson for innovators is acknowledging that successful embedding is dependent on broader material and social structures. In our case, embedding of 'Jitegemee' required significant rearrangement of interlinked activities in the domestic space. As such, a broader consideration about how an innovation influences other domains of everyday life and the wider community context (and vice versa) can give useful insights. For example, an innovator may present a solution for a problem in one activity-domain but create new social and technical problems for the entire domestic space: an increase of the 'Jitegemee' toilet may have provided a useful alternative for individual beneficiaries but it is suggested to have also contributed to community public health problems when its faecal waste started to be dumped into open drainages. Social relations also influence and are influenced by introduction of new service offerings. Marginalized groups may become excluded when new social arrangements have to be devised around an innovation. For example, when toilets that were previously open for public use in Kahawa-Soweto were converted to be used only by few families living around it as an off-plot shared toilet. The new arrangement excluded families that had previously depended on it but did not live within the newly defined proximity. As such, caution is required in how a new service offering can influence intra-community social dynamics in terms of social differentiation, exclusions, conflicts and tensions.

Finally, we contemplate that grasping the required multi-dimensionality and systemic perspectives when introducing an innovation is challenging. In fact, it may even be impossible to foresee how a new offering will embed or why. We suggest that innovators do not necessarily need to know this upfront. What is needed instead is to involve a variety of people with the in-depth contextual knowledge as coinnovators. The users themselves can especially be more actively involved in the design processes and 
all subsequent steps. This way, embedding can be seen as a process that requires continuous calibrating of new service offerings in response to users' experiences in their daily lives.

\section{Conclusion}

This paper contributes with a socio-technical, context-sensitive and actor-centred perspective to understanding embedding of innovations in highly complex and uncertain contexts. We used the empirical case of the introduction of novel sanitation service offerings in the informal settlements in Nairobi, Kenya. Our main contribution is the concept of oscillating domestic spaces. It reflects how people need to constantly respond to quickly changing and precarious preconditions by rearranging their daily practices in time and space and developing a multiplicity of alternative options and partial solutions. The approach is different from conventional engineering, economics and psychology perspectives which are highly technology and product-oriented. Our findings indicate how critical it is that innovators and service providers understand the everyday activities and strategies of informal dwellers in order to align their own perspectives with realities on the ground, and consequently to be able to design appropriate interventions and to provide relevant and timely support in the embedding process.

This study makes a contribution to the growing body of work that uses practice theory in the sustainability transitions field. Particularly, the study shows how a practice-theoretical approach helps make sense of innovation processes in highly complex and uncertain contexts like informal settlements - an empirical case which deviates significantly from the conventional application contexts of transition studies. In a wider sense, we hope that this paper's contribution has potential in finding applications beyond the informal settlement. For global North cities, growing complexity, uncertainty and fragmentation are perceived to be a future concern in basic service sectors (Shove et al., 2012). Also, neoliberal policy reforms as well as environmental concerns in the OECD seem to foster a shift towards heterogeneity and more user involvement (Furlong, 2014). Examples include the decentralizing of water, energy and sewerage systems and user involvements in car sharing, coproduction of energy and sustainable consumption. Our concept of oscillating domestic spaces may potentially provide insights on building, maintaining and transforming heterogeneous, user-centred and perhaps uncertainty-laden socio-technical systems in other geographical and socio-economic contexts.

We also reflect that a context with unmet needs, fragmented services and negative outcomes and feedbacks in basically all aspects of daily life can also create a form of 'lock-in' that is hard to escape. Such lock-in mechanisms require further explorations because our findings provide a contrast to the conventional view. In transition studies, co-existence of multiple regimes/practices is understood to 
contribute to a destabilisation that creates windows of opportunity for sustainable alternatives to flourish (Turnheim and Geels, 2012). Our conceptualization of the oscillating domestic space shows how users push for diversity in access options as a pragmatic approach to meet their basic livelihoods needs. This consequently resulted in the persistence of non-desired practices like open defecation and only a partial embedding of the seemingly superior alternative. Therefore, we suggest that introducing sustainable alternatives is not necessarily an easy task in multi-regime and unstable contexts and thus lock-in mechanisms in such contexts require further explorations.

At a more modest level, the robustness of our conceptualization of the oscillating domestic space could benefit from further testing with other urban basic service systems like water, energy and solid waste management in informal settlements and in cities in the global South. Some similarities in terms of heterogeneity of service offerings, challenges in embedding new service offerings, and unreliabilities in preconditions for practices are acknowledged in these sectors (Marshall and Farahbakhsh, 2013; Parrot et al., 2009; Peloso and Morinville, 2014; Singh et al., 2015). Lastly, this study could contribute towards future statistically representative analyses by applying previously undefined analytical elements related to uncertainties (i.e. in the SDG indicators), thereby helping to formulate timely directions and interventions for sustainable transitions.

\section{Acknowledgements}

We want to acknowledge the support and contributions of all members of SUSARA, the larger research project of which this study is part: Susanne Wymann von Dach, Heiko Gebauer, Christoph Lüthi, James T. Murphy, and Mara van Welie. We also want to acknowledge useful feedbacks received at the IST Conference in Manchester (2018), TIS seminar at TU Eindhoven (2018), the user innovation workshop at Oxford University (2018), the Global Economic Geography conference in Cologne (2018), and the Inno4sd PhD Academy in Pretoria (2017). Finally, we would like to thank the editor and two anonymous reviewers for their constructive inputs. Ahlborg co-authored this work with her post doc position funded initially by the Energy Area of Advance, Chalmers University of Technology, Sweden, and subsequently with funding from the research council Formas Mobility Grant nr. 2017-01012.7. The authors declare that they have no known competing financial interests or personal relationships that could have appeared to influence the work reported in this paper.

\section{References}

Ahlborg, H., 2017. Towards a conceptualization of power in energy transitions. Environmental Innovation and Societal Transitions 25, 122-141.

Amnesty-International, 2010. Insecurity and indignity: women's experiences in the slums of Nairobi, Kenya. Amnesty International Publications London. 
Andersson, K., Dickin, S., Rosemarin, A., 2016. Towards "Sustainable" Sanitation: Challenges and Opportunities in Urban Areas. Sustainability 8, 1289.

Avelino, F., Grin, J., Pel, B., Jhagroe, S., 2016. The politics of sustainability transitions. Journal of environmental policy \& planning 18, 557-567.

Bartlett, S., Satterthwaite, D., 1989. Introduction: Beyond the Stereotype of Slums. Environment and Urbanization 1, 2-5.

Beall, J., Guha-Khasnobis, B., Kanbur, R., 2010. Beyond the Tipping Point: A Multidisciplinary

Perspective on Urbanization and Development. Oxford University Press.

Bhagwan, J., Still, D., Buckley, C., Foxon, K., 2008. Challenges with up-scaling dry sanitation

technologies. Water Science and Technology 58, 21-27.

Boamah, F., Rothfuß, E., 2018. From technical innovations towards social practices and socio-technical transition? Re-thinking the transition to decentralised solar PV electrification in Africa. Energy

Research \& Social Science 42, 1-10.

Bourdieu, P., 1980. Le sens pratique. Ed. de minuit, France.

Cetina, K.K., Schatzki, T.R., von Savigny, E., 2005. The practice turn in contemporary theory. Routledge.

Cohen, N., llieva, R.T., 2015. Transitioning the food system: A strategic practice management approach for cities. Environmental Innovation and Societal Transitions 17, 199-217.

Collins, D., Morduch, J., Rutherford, S., Ruthven, O., 2009. Portfolios of the poor: how the world's poor live on $\$ 2$ a day. Princeton University Press.

Corburn, J., Hildebrand, C., 2015. Slum sanitation and the social determinants of women's health in Nairobi, Kenya. Journal of environmental and public health 2015.

Dreibelbis, R., Winch, P.J., Leontsini, E., Hulland, K.R., Ram, P.K., Unicomb, L., Luby, S.P., 2013. The integrated behavioural model for water, sanitation, and hygiene: a systematic review of behavioural models and a framework for designing and evaluating behaviour change interventions in infrastructure-restricted settings. BMC Public Health 13, 1015.

Edelman, M., Haugerud, A., 2005. Introduction: the anthropolgy of development and globalization. Edelman, Marc; Haugerud, Angelique. The anthropology of development and globalization: from classical political economy to contemporary neoliberalism. Malden, MA: Blackwell.

Eon, C., Breadsell, J.K., Morrison, G.M., Byrne, J., 2017. The home as a system of practice and its implications for energy and water metabolism. Sustainable Production and Consumption.

Ezeh, A., Oyebode, O., Satterthwaite, D., Chen, Y.-F., Ndugwa, R., Sartori, J., Mberu, B., MelendezTorres, G., Haregu, T., Watson, S.I., 2017. The history, geography, and sociology of slums and the health problems of people who live in slums. The lancet 389, 547-558.

Fischer, L.-B., Newig, J., 2016. Importance of Actors and Agency in Sustainability Transitions: A Systematic Exploration of the Literature. Sustainability 8, 476.

Fünfschilling, L., 2014. A dynamic model of socio-technical change: institutions, actors and technologies in interaction. University_of_Basel.

Furlong, K., 2014. STS beyond the "modern infrastructure ideal": Extending theory by engaging with infrastructure challenges in the South. Technology in Society 38, 139-147.

Geels, F.W., 2011. The multi-level perspective on sustainability transitions: Responses to seven criticisms. Environmental Innovation and Societal Transitions 1, 24-40.

Giddens, A., 1979. Agency, structure, Central problems in social theory. Springer, pp. 49-95.

Giddens, A., 1984. The constitution of society: Outline of the theory of structuration. Univ of California Press.

Gilbert, A., 2007. The return of the slum: does language matter? International Journal of Urban and Regional Research 31, 697-713.

Gram-Hanssen, K., 2011. Understanding change and continuity in residential energy consumption. Journal of Consumer Culture 11, 61-78.

Greene, M., 2018. Socio-technical transitions and dynamics in everyday consumption practice. Global Environmental Change 52, 1-9.

Habitat, U., 2016. Slums Almanac 2015-2016: tracking improvement in the lives of slum dwellers. UNHabitat, Nairobi. 
Hägerstrand, T., 1970. What about people in regional science?, Papers of the Regional Science Association. Springer, pp. 6-21.

Hansen, T., Coenen, L., 2015. The geography of sustainability transitions: review, synthesis and reflections on an emergent research field. Environmental Innovation and Societal Transitions 17, 92109.

Hargreaves, T., Longhurst, N., Seyfang, G., 2013. Up, down, round and round: connecting regimes and practices in innovation for sustainability. Environment and Planning A 45, 402-420.

Jaglin, S., 2016. Is the network challenged by the pragmatic turn in African cities? Urban transition and hybrid delivery configurations. Routledge.

Jones, A., Murphy, J.T., 2011. Theorizing practice in economic geography: Foundations, challenges, and possibilities. Progress in Human Geography 35, 366-392.

Kalan, J., 2011. The Silicon Valley of Shit: Nairobi Is Ground Zero for Sanitation Innovation. GOOD. Karanja, I., Makau, J., 2012. An inventory of the slums in Nairobi. UN Office for the Coordination of Humanitarian Affairs, Nairobi.

Kariuki, M., Schwartz, J., 2005. Small-scale private service providers of water supply and electricity: A review of incidence, structure, pricing, and operating characteristics. World Bank Publications. Katukiza, A., Ronteltap, M., Niwagaba, C., Foppen, J., Kansiime, F., Lens, P., 2012. Sustainable sanitation technology options for urban slums. Biotechnology advances 30, 964-978.

Khalid, R., Sunikka-Blank, M., 2017. Homely social practices, uncanny electricity demands: Class, culture and material dynamics in Pakistan. Energy Research \& Social Science 34, 122-131.

Korten, D.C., 1980. Community organization and rural development: A learning process approach. Public administration review, 480-511.

Larsen, T.A., Hoffmann, S., Lüthi, C., Truffer, B., Maurer, M., 2016. Emerging solutions to the water challenges of an urbanizing world. Science 352, 928-933.

Lawhon, M., Nilsson, D., Silver, J., Ernstson, H., Lwasa, S., 2017. Thinking through heterogeneous infrastructure configurations. Urban Studies, 0042098017720149.

Letema, S., van Vliet, B., van Lier, J.B., 2014. Sanitation policy and spatial planning in urban East Africa: Diverging sanitation spaces and actor arrangements in Kampala and Kisumu. Cities 36, 1-9.

Lüthi, C., McConville, J., Kvarnström, E., 2010. Community-based approaches for addressing the urban sanitation challenges. International Journal of Urban Sustainable Development 1, 49-63.

Markard, J., Raven, R., Truffer, B., 2012. Sustainability transitions: An emerging field of research and its prospects. Research policy 41, 955-967.

Marshall, R.E., Farahbakhsh, K., 2013. Systems approaches to integrated solid waste management in developing countries. Waste Management 33, 988-1003.

McMeekin, A., Southerton, D., 2012. Sustainability transitions and final consumption: practices and socio-technical systems. Technology Analysis \& Strategic Management 24, 345-361.

McSorley, B., 2012. Jitegemee - using innovation to tackle the urban sanitation challenge, Oxfam Policy \& Practice Blog. Oxfam.

Mohanty, S., 2018. She is where muck is!, Oxfam Policy \& Practice Blog. Oxfam.

O'Reilly, K., 2016. From toilet insecurity to toilet security: creating safe sanitation for women and girls. Wiley Interdisciplinary Reviews: Water 3, 19-24.

O'Keefe, M., Lüthi, C., Tumwebaze, I.K., Tobias, R., 2015. Opportunities and limits to market-driven sanitation services: evidence from urban informal settlements in East Africa. Environment and Urbanization 27, 421-440.

Ockwell, D., Byrne, R., Hansen, U.E., Haselip, J., Nygaard, I., 2018. The uptake and diffusion of solar power in Africa. Energy Research \& Social Science.

Ostrom, E., 1996. Crossing the great divide: coproduction, synergy, and development. World development 24, 1073-1087.

Otsuki, K., 2016. Infrastructure in informal settlements: co-production of public services for inclusive governance. Local Environment, 1-16.

Oxfam, 2016. Container based sanitation could solve the world's toilet problems, Oxfam Policy \& Practice Blog. Oxfam. 
Parrot, L., Sotamenou, J., Dia, B.K., 2009. Municipal solid waste management in Africa: Strategies and livelihoods in Yaoundé, Cameroon. Waste management 29, 986-995.

Peloso, M., Morinville, C., 2014. 'Chasing for water': Everyday practices of water access in peri-urban Ashaiman, Ghana. Water Alternatives 7.

Ramani, S.V., SadreGhazi, S., Duysters, G., 2012. On the diffusion of toilets as bottom of the pyramid innovation: Lessons from sanitation entrepreneurs. Technological Forecasting and Social Change 79, 676-687.

Reckwitz, A., 2002. Toward a theory of social practices a development in culturalist theorizing.

European journal of social theory 5, 243-263.

Robeyns, I., 2005. The capability approach: a theoretical survey. Journal of human development 6, 93117.

Rogers, E.M., 2010. Diffusion of innovations. Simon and Schuster.

Satterthwaite, D., Mitlin, D., Bartlett, S., 2015. Is it possible to reach low-income urban dwellers with good-quality sanitation? SAGE Publications Sage UK: London, England.

Schatzki, T.R., 2002. The site of the social: A philosophical account of the constitution of social life and change. Penn State Press.

Schramm, S., Wright-Contreras, L., 2017. Beyond passive consumption: Dis/ordering water supply and sanitation at Hanoi's urban edge. Geoforum 85, 299-310.

Schwartz, K., Tutusaus Luque, M., Rusca, M., Ahlers, R., 2015. (In) formality: the meshwork of water service provisioning. Wiley Interdisciplinary Reviews: Water 2, 31-36.

Sen, A., 1993. Capability and well-being, in: Nussbaum, M.S., A (Ed.), The quality of life. Oxford University Press, Oxford, pp. 30-53.

Sheuya, S.A., 2008. Improving the health and lives of people living in slums. Annals of the New York Academy of Sciences 1136, 298-306.

Shove, E., 2004. Efficiency and consumption: technology and practice. Energy \& Environment 15, 10531065.

Shove, E., Pantzar, M., Watson, M., 2012. The dynamics of social practice: everyday life and how it changes. Sage Publications.

Shove, E., Trentmann, F., Wilk, R., 2009. Time, consumption and everyday life: Practice, materiality and culture. Berg.

Shove, E., Walker, G., 2007. CAUTION! Transitions ahead: politics, practice, and sustainable transition management. Environment and Planning A 39, 763-770.

Shove, E., Walker, G., 2010. Governing transitions in the sustainability of everyday life. Research policy 39, 471-476.

Sijbesma, C., 2006. Where softness matters most: Scaling up dry toilet programmes in developing countries, The 2nd International Dry Toilet Conference, Tampere, Finland.

Singh, R., Wang, X., Mendoza, J.C., Ackom, E.K., 2015. Electricity (in) accessibility to the urban poor in developing countries. Wiley Interdisciplinary Reviews: Energy and Environment 4, 339-353.

Spaargaren, G., Oosterveer, P., Loeber, A., 2013. Food practices in transition: changing food consumption, retail and production in the age of reflexive modernity. Routledge.

Stengers, I., 2010. Including Nonhumans in Political Theory: Opening the Pandora's Box?, Political matter: Technoscience, democracy public life. University of Minnesota Press, pp. 3-33.

Stengers, I., 2013. Introductory notes on an ecology of practices. Cultural Studies Review 11, 183-196.

Strengers, Y., 2013. Smart energy technologies in everyday life: Smart Utopia? Springer.

Thieme, T.A., 2017. The hustle economy: Informality, uncertainty and the geographies of getting by. Progress in Human Geography, 0309132517690039.

Tilley, E., Bieri, S., Kohler, P., 2013. Sanitation in developing countries: a review through a gender lens. Journal of Water Sanitation and Hygiene for Development 3, 298-314.

Turnheim, B., Geels, F.W., 2012. Regime destabilisation as the flipside of energy transitions: Lessons from the history of the British coal industry (1913-1997). Energy Policy 50, 35-49.

Ulsrud, K., Rohracher, H., Winther, T., Muchunku, C., Palit, D., 2018. Pathways to electricity for all: What makes village-scale solar power successful? Energy Research \& Social Science 44, 32-40. 
UNSD, 2015. Millennium Development Goals Indicators, Proportion of the population using improved sanitation facilities, urban. United Nations Statistics Division, New York.

van Welie, M.J., Cherunya, P.C., Truffer, B., Murphy, J.T., 2018. Analysing transition pathways in developing cities: The case of Nairobi's splintered sanitation regime. Technological Forecasting and Social Change.

van Welie, M.J., Truffer, B., Gebauer, H., 2019. Innovation challenges of utilities in informal settlements: combining a capabilities and regime perspective. Environmental Innovation and Societal Transitions.

Watson, M., 2012. How theories of practice can inform transition to a decarbonised transport system. Journal of Transport Geography 24, 488-496.

Wenger, E., 1998. Communities of practice: Learning, meaning, and identity. Cambridge university press.

WHO/UNICEF, March 2018. JMP Methodology 2017: Update and SDG baselines. WHO/UNICEF. Wieczorek, A.J., 2017. Sustainability transitions in developing countries: Major insights and their implications for research and policy. Environmental Science \& Policy.

Wittmayer, J.M., Avelino, F., van Steenbergen, F., Loorbach, D., 2016. Actor roles in transition: Insights from sociological perspectives. Environmental Innovation and Societal Transitions.

WSUP, 2011. When are communal or public toilets an appropriate option? WSUP.

Yap, X.-S., Truffer, B., 2019. Shaping selection environments for industrial catch-up and sustainability transitions: A systemic perspective on endogenizing windows of opportunity. Research policy 48, 10301047. 


\section{Appendix 1}

List of interview respondents using anonymised codes and names

\begin{tabular}{|c|c|c|}
\hline \multicolumn{3}{|c|}{ 1. Women inhabitants from 3 villages } \\
\hline \multicolumn{3}{|c|}{ Mukuru-Rorie (MR) } \\
\hline Respondents & Age range (years) & Occupation \\
\hline MR1 & $21-30$ & Industry part-time casual jobs \\
\hline MR2 & $31-40$ & Community Health Volunteer; Jitegemee beneficiary \\
\hline MR3 & $31-40$ & Field project officer in an NGO; Jitegemee beneficiary \\
\hline MR4 & $31-40$ & Community Health Volunteer \\
\hline MR5 & $41-50$ & Street-food seller \\
\hline MR6 & $31-40$ & Unemployed \\
\hline MR7 & $21-30$ & Unemployed \\
\hline MR8 & $41-50$ & Unemployed (unwell from effects of industry jobs) \\
\hline MR9 & $41-50$ & Street vegetable business \\
\hline MR10 & $41-40$ & Runs a small retail shop; Jitegemee beneficiary \\
\hline MR11 & $31-40$ & School teacher; Jitegemee beneficiary \\
\hline Case 1: Clara & $31-40$ & Intermittent jobs (hawking, house-cleaning); Jitegemee beneficiary \\
\hline FGD 4 (8 participants) & Adults & Various \\
\hline FGD 5 (10 participants) & Adults & Various \\
\hline \multicolumn{3}{|l|}{ Mathare-Bondeni (MB) } \\
\hline Respondents & Age range (years) & Occupation \\
\hline MB1 & $51-60$ & Social worker \\
\hline MB2 & $31-40$ & $\begin{array}{l}\text { Intermittent jobs (political campaigning; data collection; clothes } \\
\text { business) }\end{array}$ \\
\hline MB3 & $41-50$ & Runs an unregistered local bar \\
\hline MB4 & $51-60$ & Unemployed \\
\hline MB5 & $21-30$ & Runs a small retail shop \\
\hline MB6 & $41-50$ & Runs an unregistered local bar \\
\hline Case 2: Hanna & 49 & Street peanut business \\
\hline MB8 & $31-40$ & Street vegetable business \\
\hline MB9 & $21-30$ & Intermittent jobs (hawking either tea or clothes) \\
\hline MB10 & $61-70$ & Runs an unregistered local bar \\
\hline FGD 1 (10 participants) & Adults & Various \\
\hline \multicolumn{3}{|l|}{ Kahawa-Soweto (KS) } \\
\hline Respondents & Age range (years) & Occupation \\
\hline KS1 & $41-50$ & Intermittent jobs (hawking \& cultivating) \\
\hline KS2 & $50-60$ & Unemployed (dependent on children) \\
\hline KS3 & $31-40$ & Runs a local restaurant \\
\hline KS4 & $51-60$ & Field project officer for a local NGO \\
\hline KS5 & $41-50$ & Street clothes business in the city \\
\hline KS6 & $31-40$ & Farming and intermittent house cleaning and cultivating jobs \\
\hline KS7 & $31-40$ & Hawking \& Community Health Volunteer \\
\hline KS8 & $41-50$ & $\begin{array}{l}\text { Local fruits and vegetables distributor, and intermittent cultivating } \\
\text { jobs }\end{array}$ \\
\hline KS9 & $41-50$ & Sells charcoal from her house \\
\hline Case 3: Grace & $41-50$ & Intermittent jobs (hawking, cultivating, house-cleaning ) \\
\hline FGD 2 (10 participants) & Adults & Various \\
\hline FGD 3 (10 participants) & Teenagers & Various \\
\hline \multicolumn{3}{|c|}{ 2. Other experts and informants } \\
\hline NGO rep. & & NGO representatives $(1-22)$ \\
\hline CHEO & & Community Health Extension Officers (1-3) \\
\hline LMR & & Local male residents (1-3) \\
\hline LAL & & Local administrative leaders (1-9) \\
\hline
\end{tabular}

